\title{
RESEARCH
}

Open Access

\section{Simulation of semilunar valve function: computer-aided design, 3D printing and flow assessment with MR}

\author{
Nabil Hussein ${ }^{1}$, Pascal Voyer-Nguyen ${ }^{2}$, Sharon Portnoy ${ }^{3}$, Brandon Peel ${ }^{2}$, Eric Schrauben ${ }^{3}$, \\ Christopher Macgowan ${ }^{3}$ and Shi-Joon Yoo ${ }^{4^{*}}$ (i)
}

\begin{abstract}
Background: The structure of the valve leaflets and sinuses are crucial in supporting the proper function of the semilunar valve and ensuring leaflet durability. Therefore, an enhanced understanding of the structural characteristics of the semilunar valves is fundamental to the evaluation and staging of semilunar valve pathology, as well as the development of prosthetic or bioprosthetic valves. This paper illustrates the process of combining computer-aided design (CAD), 3D printing and flow assessment with 4-dimensional flow magnetic resonance imaging (MRI) to provide detailed assessment of the structural and hemodynamic characteristics of the normal semilunar valve.
\end{abstract}

Methods: Previously published geometric data on the aortic valve was used to model the 'normal' tricuspid aortic valve with a CAD software package and 3D printed. An MRI compatible flow pump with the capacity to mimic physiological flows was connected to the phantom. A peak flow rate of $100 \mathrm{~mL} / \mathrm{s}$ and heart rate of 60 beats per minute were used. MRI measurements included cine imaging, 2D and 4D phase-contrast imaging to assess valve motion, flow velocity and complex flow patterns.

Results: Cine MRI data showed normal valve function and competency throughout the cardiac cycle in the 3Dprinted phantom. Quantitative analysis of 4D Flow data showed net flow through 2D planes proximal and distal to the valve were very consistent $(26.03 \mathrm{~mL} / \mathrm{s}$ and $26.09 \mathrm{~mL} / \mathrm{s}$, respectively). Measurements of net flow value agreed closely with the flow waveform provided to the pump $(27.74 \mathrm{~mL} / \mathrm{s})$, confirming $4 \mathrm{D}$ flow acquisition in relation to the pump output. Peak flow values proximal and distal to the valve were $78.4 \mathrm{~mL} / \mathrm{s}$ and $63.3 \mathrm{~mL} / \mathrm{s}$, respectively. Particle traces of flow from 4D-phase contrast MRI data demonstrated flow through the valve into the ascending aorta and vortices within the aortic sinuses, which are expected during ventricular diastole.

Conclusion: In this proof of concept study, we have demonstrated the ability to generate physiological 3D-printed aortic valve phantoms and evaluate their function with cine- and 4D Flow MRI. This technology can work synergistically with promising tissue engineering research to develop optimal aortic valve replacements, which closely reproduces the complex function of the normal aortic valve.

Keywords: Aortic valve, 4D-flow MRI, 3D-printing, Computer-aided design

\footnotetext{
* Correspondence: shi-joon.yoo@sickkids.ca

${ }^{4}$ Department of Diagnostic Imaging and Division of Cardiology, Department of Paediatrics Hospital for Sick Children, University of Toronto, 555 University Avenue, Toronto, Ontario M5G1X8, Canada

Full list of author information is available at the end of the article
}

(C) The Author(s). 2020 Open Access This article is distributed under the terms of the Creative Commons Attribution 4.0 International License (http://creativecommons.org/licenses/by/4.0/), which permits unrestricted use, distribution, and reproduction in any medium, provided you give appropriate credit to the original author(s) and the source, provide a link to the Creative Commons license, and indicate if changes were made. 


\section{Introduction}

The aortic and pulmonary valves are collectively called the semilunar valves as they consist of three semilunar shaped leaflets that show a gentle concave curvature when viewed from above. These valves are contained within the arterial root, which has three visible round outward protrusions called the sinuses of Valsalva. The structure of both the valve leaflets and sinuses are crucial in supporting the proper function of the semilunar valve and ensuring durability of the valve leaflets, which open and close approximately 100,000 times daily without any resting period. An enhanced understanding of the structural characteristics of the semilunar valves is therefore fundamental to the evaluation and staging of semilunar valve pathology, as well as the development of prosthetic or bioprosthetic valves. We hypothesized that a combination of computer-aided design (CAD), 3D printing and flow assessment with magnetic resonance imaging (MRI) would provide an unprecedented opportunity for detailed assessment of the structural and hemodynamic characteristics of both normal semilunar valves and pathologic conditions such as isolated aortic and pulmonary valve diseases and connective tissue diseases affecting the arterial roots. This paper illustrates the process of $C A D$ and $3 \mathrm{D}$ printing of a semilunar valve phantom and the assessment of valve function using 4dimensional (4D) flow MRI.

\section{Method}

Previously published data using either pathology specimens or medical imaging were used to model the structure of the 'normal' tricuspid aortic valve with a CAD software package (SolidWorks, Waltham, Massachusetts, USA) (Figs. 1, 2) [1-7]. The design of the aortic root incorporated the sinuses of Valsalva, sinotubular junction, and ascending aorta. A cylinder with the dimension of the distal left ventricular outflow tract was modeled to complete the aortic valve phantom (Fig. 3).

The stereolithography (STL) files were then generated and printed on a 3D printer (Objet 500 Connex 3, Stratsys Ltd., Eden Prairie, MN, USA). After multiple trials with various materials, a mixture of Agilus Clear and VeroWhite resin material was used to create the aortic walls and sinus and TangoPlus resin was used for the individual valve leaflets. The leaflet thickness was $0.6 \mathrm{~mm}$. An MRI compatible flow pump (CardioFlow 5000, Shelley Medical Imaging Technologies, London, Ontario, Canada) with the capacity to mimic physiological flows was connected to the aortic flow phantom. The fluid reservoir, flow pump and phantom model were all connected in series on a single loop circuit. To mimic diastolic arterial pressure, the circuit between the phantom return line and reservoir was open and elevated such that the phantom sits $1088 \mathrm{~mm}$ below the water level. This setup results in a diastolic pressure equivalent to $80 \mathrm{mmHg}$ at the phantom's ascending aorta. The pump was programmed to generate a flow pattern, with a peak flow rate of $100 \mathrm{~mL} / \mathrm{s}$, simulating a normal aortic waveform (Fig. 4). The heart rate was set to 60 beats per minute. Prior to its introduction into the MRI scanner, the flow circuit was carefully tested on the bench, including graduated cylinder/stopwatch measurements to verify the accuracy of the pump. Following these preliminary tests, MRI data were acquired on a $3 \mathrm{~T}$ Prisma system (Siemens Healthineers, Erlangen, Germany).

MRI measurements included:

1) Cine imaging - to assess valve motion throughout the cardiac cycle

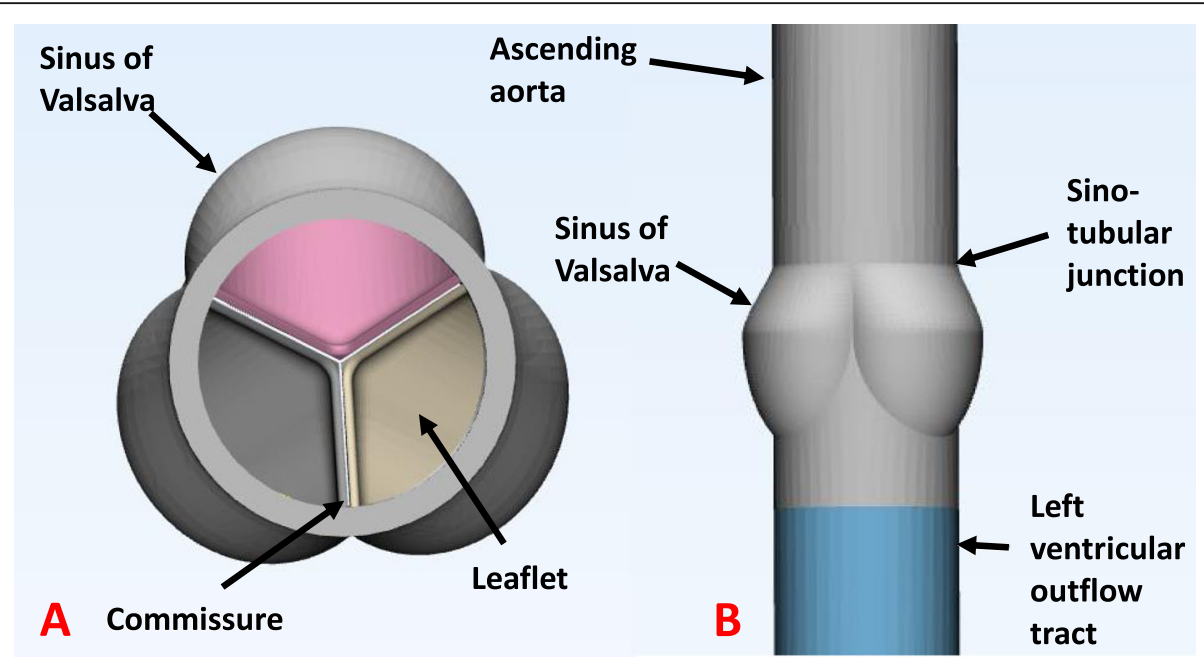

Fig. 1 Normal tricuspid aortic valve modelled using computer aided design based on geometry obtained from literature. a Superior view looking down the ascending aorta to visualize the aortic valve leaflets. $\mathbf{b}$ Lateral view of aortic valve phantom incorporating aortic root structures 

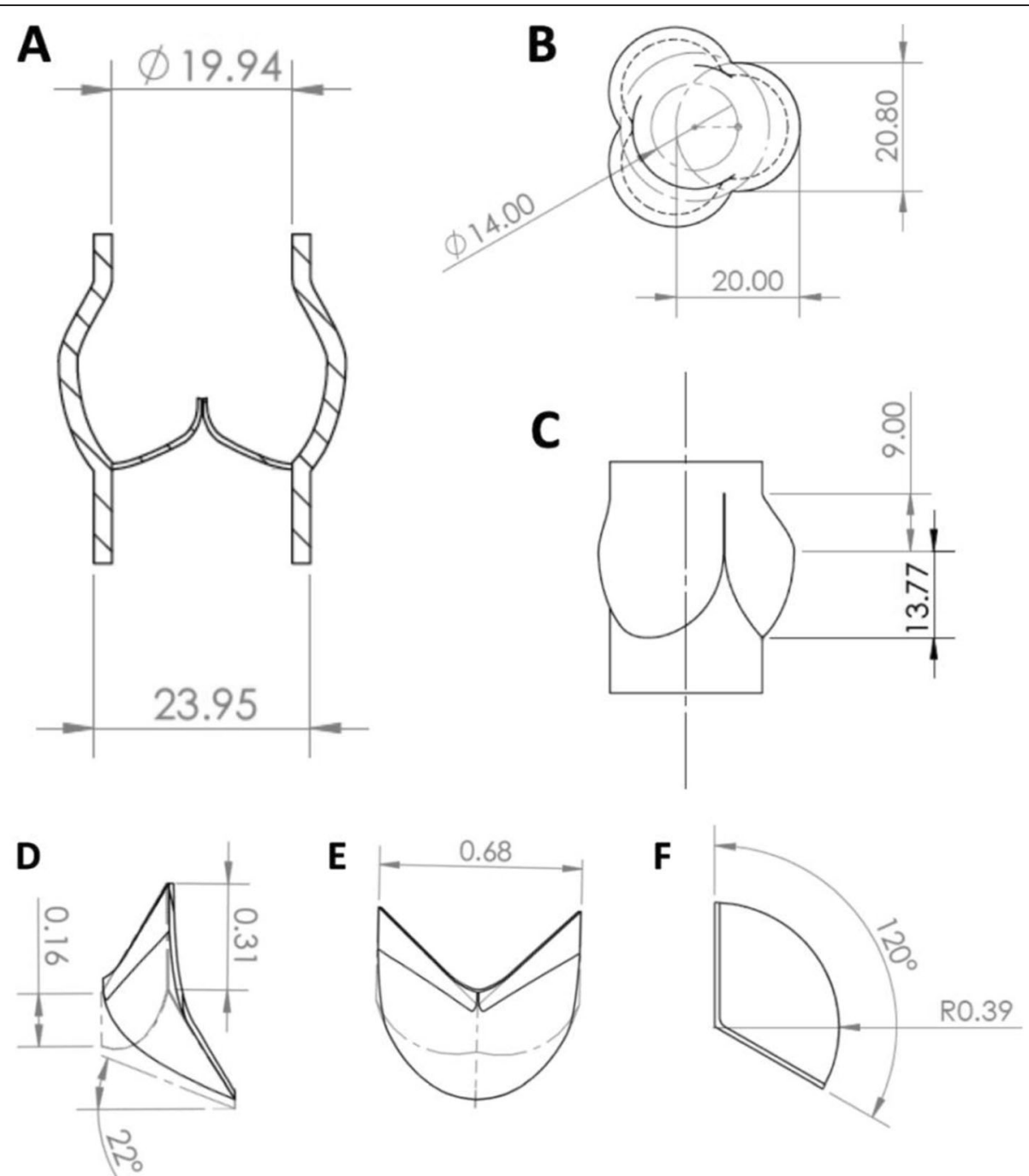

Fig. 2 2D sketches of aortic root and valve leaflet geometry $(\mathrm{mm})$. a Coronal view of the aortic root. Wall thickness $2 \mathrm{~mm}$. b Cross-sectional View of aortic root. $\mathbf{c}$ Lateral view of aortic root. $\mathbf{d}$ Lateral view of valve leaflet. e Frontal view of valve leaflet. $\mathbf{f}$ Superior view of valve leaflet

2) 2D phase contrast flow imaging - to measure flow velocity above and below the valve and assess for evidence of aortic stenosis (significant flow acceleration across the valve) or aortic regurgitation (retrograde flow) and to compare the data with ground truths.

3) 4D phase-contrast flow imaging - to visualize and analyze complex flow patterns using vector fields and path lines (Table 1).

\section{Results}

A live video recording demonstrating the function of the 3D printed valve is provided in Fig. 5 (and Additional file 1: Video S1). Valve opening and closure during systole and diastole, respectively, is clearly visualized.

Cine MRI data, providing both short and long axis views of the functioning valve are shown in Fig. 6 (and
Additional file 2: Video S2). During systole the leaflets opened instantaneously allowing unobstructed flow through the valve and the leaflets closed effectively with cessation of systolic forward flow. Visualization and quantitative analysis of 4D Flow data was performed using a commercial software package (4D Flow, Siemens, Erlangen, Germany). Retrospective measurements of net flow through $2 \mathrm{D}$ planes placed proximal and distal to the valve were very consistent $(26.03 \mathrm{~mL} / \mathrm{s}$ and $26.09 \mathrm{~mL} / \mathrm{s}$, respectively). Flow waveforms measured at these two planes are provided in Fig. 7. Peak flow values proximal and distal to the valve were $78.4 \mathrm{~mL} /$ $\mathrm{s}$ and $63.3 \mathrm{~mL} / \mathrm{s}$, respectively. Measurements of net flow value agreed closely with the integral of the flow waveform provided to the CardioFlow 5000 (27.74 $\mathrm{mL} / \mathrm{s}$ ), confirming $4 \mathrm{D}$ flow acquisition in relation to the pump output. 

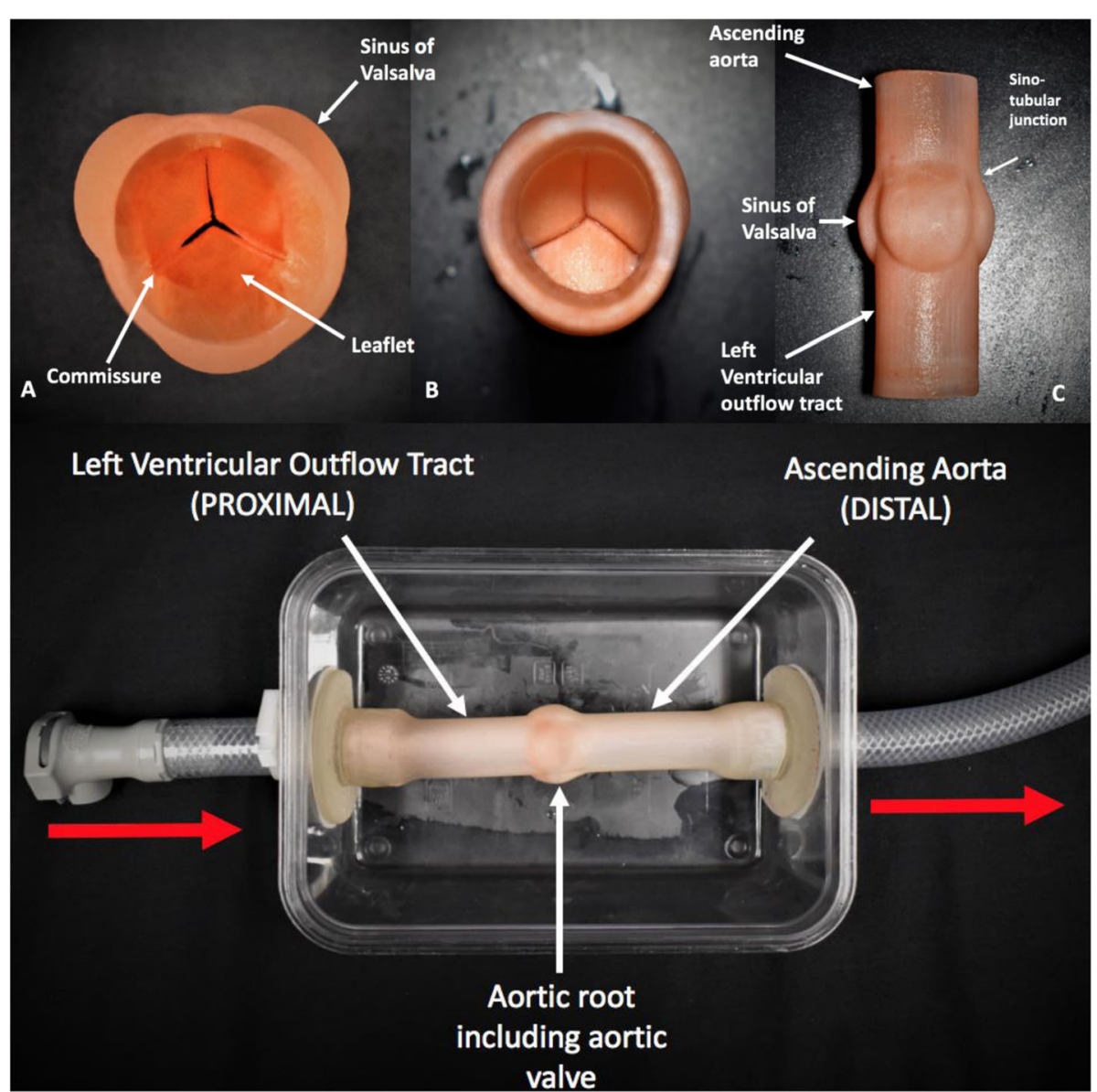

Fig. 3 Top Panel: 3D printed tricuspid aortic valve phantom. a Superior view looking down the ascending aorta to visualize the aortic valve leaflets. $\mathbf{b}$ Inferior view looking up the left ventricular outflow tract to the base of the closed valve. $\mathbf{c}$ Lateral view of aortic valve phantom incorporating aortic root structures. Bottom Panel: Piping connected to phantom which attaches to the physiological MRI compatible pump. Red arrows show the direction of flow through the phantom

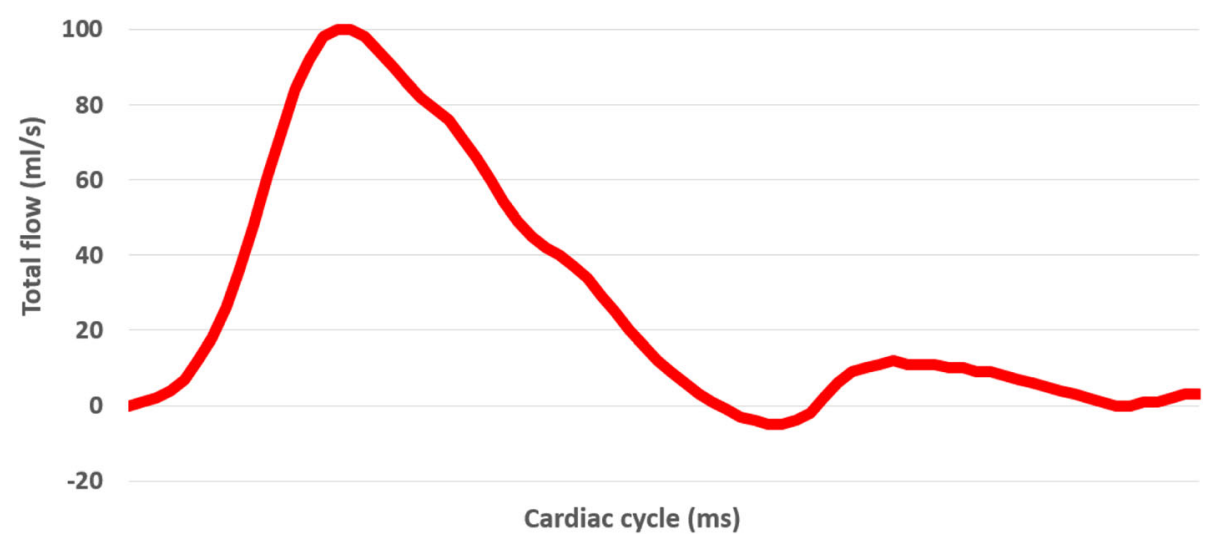

Fig. 4 Normal aortic waveform programmed to flow pump over one cardiac cycle. Peak flow rate set at $100 \mathrm{~mL} / \mathrm{s}$ 
Table 1 Pulse sequence parameters from the Digital Imagining and Communications in Medicine (DICOM) data for each of the modalities used

\begin{tabular}{|c|c|c|c|c|c|c|c|c|c|}
\hline & Scan duration (minutes) & $\begin{array}{l}2 \mathrm{D} / \\
3 \mathrm{D}\end{array}$ & $\begin{array}{l}\text { In-plane } \\
\text { resolution }\left(\mathrm{mm}^{2}\right)\end{array}$ & $\begin{array}{l}\text { Slice thickness } \\
(\mathrm{mm})\end{array}$ & $\begin{array}{l}\text { TR/TE } \\
\text { (ms) }\end{array}$ & Field of View & $\begin{array}{l}\text { Matrix } \\
\text { size }\end{array}$ & $\begin{array}{l}\text { Flip } \\
\text { angle }\left(^{\circ}\right)\end{array}$ & $\begin{array}{l}\text { Venc } \\
(\mathrm{cm} / \mathrm{s})\end{array}$ \\
\hline 4D Flow & $\begin{array}{l}11.7 \text { (in-plane GRAPPA } \\
\text { acceleration factor }=3 \text { ) }\end{array}$ & $3 \mathrm{D}$ & $1.6 \times 1.6$ & 1.6 & $\begin{array}{l}48.6 / \\
3.5\end{array}$ & $\begin{array}{l}200 \times 156 \times \\
64 \mathrm{~mm}^{3}\end{array}$ & $\begin{array}{l}128 \times \\
102 \times 40\end{array}$ & 7 & 100 \\
\hline $\begin{array}{l}\text { Phase } \\
\text { Contrast }\end{array}$ & 0.5 & $2 \mathrm{D}$ & $1.0 \times 1.0$ & $\begin{array}{l}5 \text { (single slice } \\
\text { acquisition) }\end{array}$ & $\begin{array}{l}50.9 / \\
4.1\end{array}$ & $\begin{array}{l}200 \times 119 \\
\mathrm{~mm}^{2}\end{array}$ & $192 \times 116$ & 25 & 70 \\
\hline $\begin{array}{l}\text { Cine } \\
\text { (axial) }\end{array}$ & 1.5 & $2 \mathrm{D}$ & $1.0 \times 1.2$ & $\begin{array}{l}3 \text { ( } 5 \text { slices } \\
\text { acquired) }\end{array}$ & $\begin{array}{l}58.8 / \\
3.3\end{array}$ & $\begin{array}{l}200 \times 119 \\
\mathrm{~mm}^{2}\end{array}$ & $192 \times 99$ & 12 & $\mathrm{n} / \mathrm{a}$ \\
\hline $\begin{array}{l}\text { Cine } \\
\text { (coronal) }\end{array}$ & 1.5 & $2 \mathrm{D}$ & $1.2 \times 1.3$ & $\begin{array}{l}3 \text { (3 slices } \\
\text { acquired) }\end{array}$ & $\begin{array}{l}57.5 / \\
3.3\end{array}$ & $\begin{array}{l}224 \times 133 \\
\mathrm{~mm}^{2}\end{array}$ & $192 \times 99$ & 12 & $\mathrm{n} / \mathrm{a}$ \\
\hline
\end{tabular}

Particle traces of flow from 4D-phase contrast MRI data demonstrated flow through the valve into the ascending aorta, as well as vortices within the aortic sinuses, which are expected during ventricular diastole. There was a small degree of retrograde flow during diastole, suggestive of regurgitation. (Fig. 8 + Additional file 3: Video S3).

2D contrast imaging of flow volumes were less consistent than 4D with net flow proximal and distal to the valve measuring $20.60 \mathrm{~mL}$ and $27.20 \mathrm{~mL}$, respectively. Peak flow values proximal and distal to the valve were $74.6 \mathrm{~mL} / \mathrm{s}$ and $67.6 \mathrm{~mL} / \mathrm{s}$ respectively.

\section{Discussion}

The semilunar valves are uniquely structured to open and close without the aid of the chords and papillary muscles. The tricuspid semilunar valve with properly sized and shaped sinuses of Valsalva appears to be the ideal configuration for optimal hemodynamics, compared to mono or bicuspid variants [4, 8-10]. Any alteration in the number of valve leaflets, the size of the valve annulus and the size and shape of the sinuses may result in inadequate flow or turbulence across the valvular orifice and damage to the valve leaflets. Both aortic and pulmonary valve diseases are not uncommon and require replacement of the diseased valve with a prosthetic or bioprosthetic valve through surgery or intervention [11-13]..

3D printing of patient specific aortic root phantoms has previously been used successfully to develop procedural simulations for in vitro transcatheter aortic valve replacements (TAVR) and to quantitatively assess post-TAVR aortic root strain and potential incidence of paravalvular leak using computed tomography [14]. Our pilot study provides the first demonstration of $3 \mathrm{D}$ printing of flexible semilunar valves fabricated with $\mathrm{CAD}$, followed by detailed assessments of function and flow using cine- and 4D Flow MRI.

The results generated further validate the efficacy of using additive manufacturing as a feasible and effective methodology to assess semilunar valve function. In addition, it has been shown that $4 \mathrm{D}$ flow MRI can be used in phantoms to investigate the complex flow patterns within the aortic root, which are crucial in evaluating valve leaflet closure and coronary artery perfusion. This method can support ongoing work in the field of computational -fluid dynamics (CFD), which has analyzed normal aortic valve function, in addition to simulating surgical repairs of the aortic root [15-18].

The workflow demonstrated in this paper can be applied to the investigation of: 1) the structural

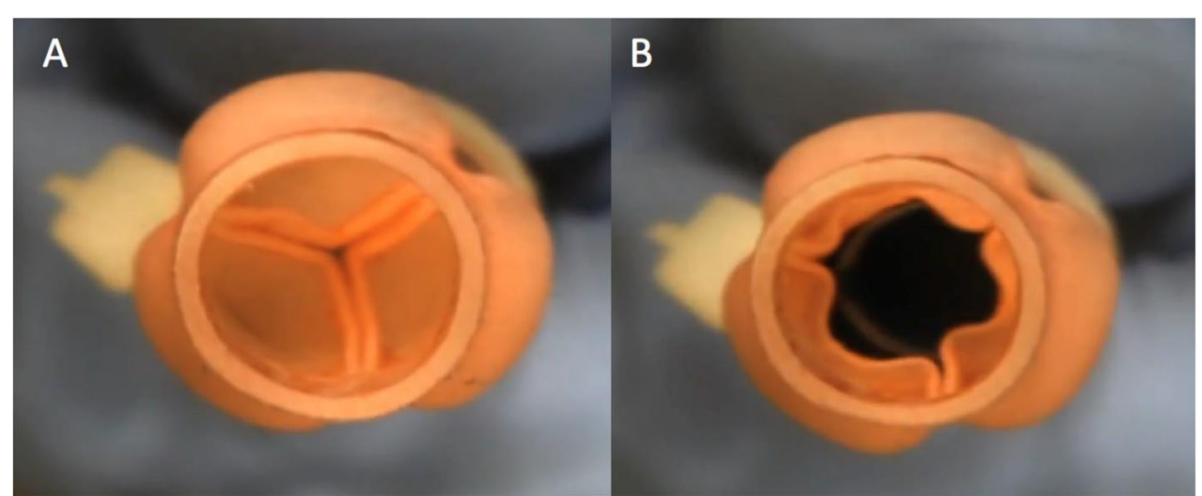

Fig. 5 View from above the 3D printed aortic valve demonstrating the valve closing and opening in response to pulsatile flow. a Valve leaflets closing during diastole. $\mathbf{b}$ Valve leaflets opening during systole. (Corresponding video files attached - Additional file 1: Video S1) 

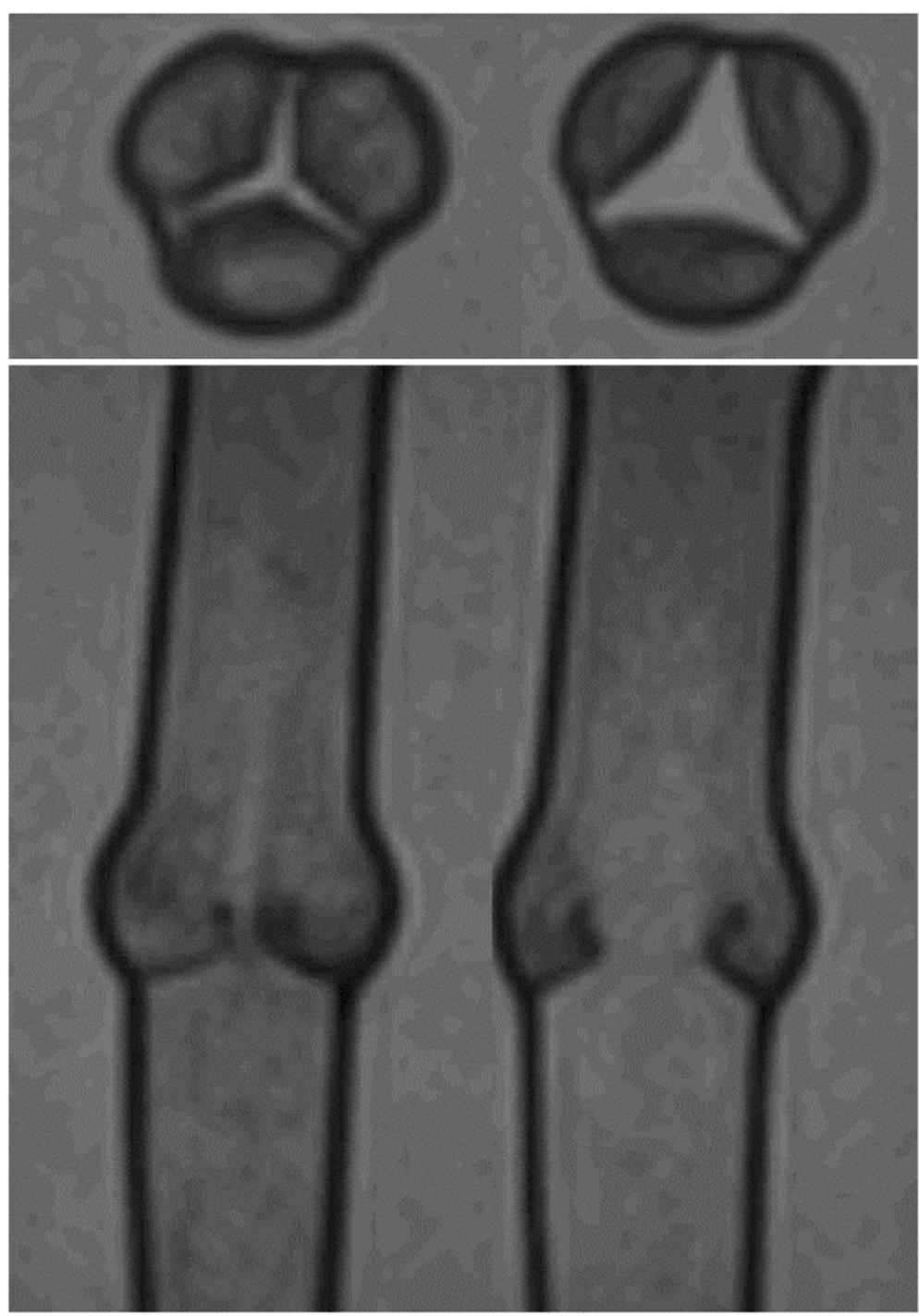

Fig. 6 Cine MRI images showing aortic valve phantom in simulated systole in short and long axis planes. Left image shows the valve leaflets closed. Right image shows leaflets open. (Corresponding video files attached - Additional file 2: Video S2)

requirements for optimal function and durability of the semilunar valve and the sinuses of Valsalva, 2) the study of the hemodynamic changes in association with abnormal valve leaflet and sinus configuration such as various forms of bicuspid and quadricuspid valves, and 3) the effect of the dilated aortic root on aortic valve anatomy and function in systemic connective tissue diseases such as Marfan and Loeys-Dietz syndromes. Although the listed features can be assessed in living individuals, invivo studies are associated with numerous confounding factors such as ventricular function, heart rate, distal vascular resistance and anatomical variations. Inevitably this method requires a large study population to prove the given hypotheses. As any number of combinations of anatomical and hemodynamic variations can be fabricated with $\mathrm{CAD}$ and $3 \mathrm{D}$ printing, with the other confounding factors kept constant, the structural and functional importance of each component of the valve and sinus can be isolated and assessed in detail. Fabrication of individualized semilunar valve phantoms with computer and phantom flow dynamic studies may ultimately allow optimized design of bioprinted implantable valves. The experimental setting with phantoms can also be used for validation of the flow assessment tools including Doppler ultrasound, 2D- and 4D-flow MRI using precisely calibrated flow pumps. This methodology streamlines the process from prototyping to valve testing, reducing the time required to optimize the structure of the semilunar valve.

Potential areas for improvement of the demonstrated workflow include: quality of $3 \mathrm{D}$ print material, the CAD technique for valve design and the physiological fidelity 


\section{D Proximal vs 2D Distal}

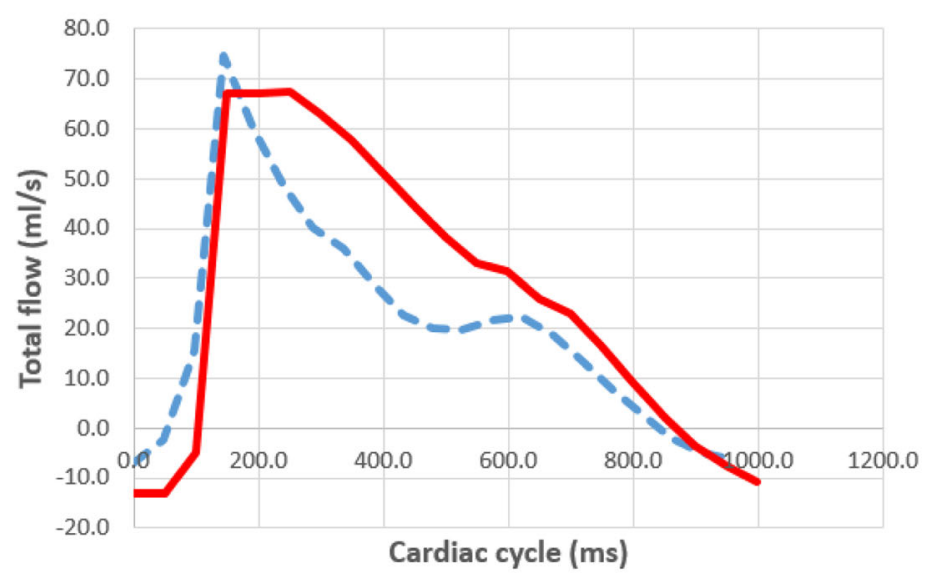

2D Net Volume $(\mathrm{mL})$ :

Proximal: $\quad 20.60$

Distal: $\quad 27.20$

Difference: $\quad 6.5$

\%: $\quad 24 \%$

-2D Proximal Slice

2D Distal Slice

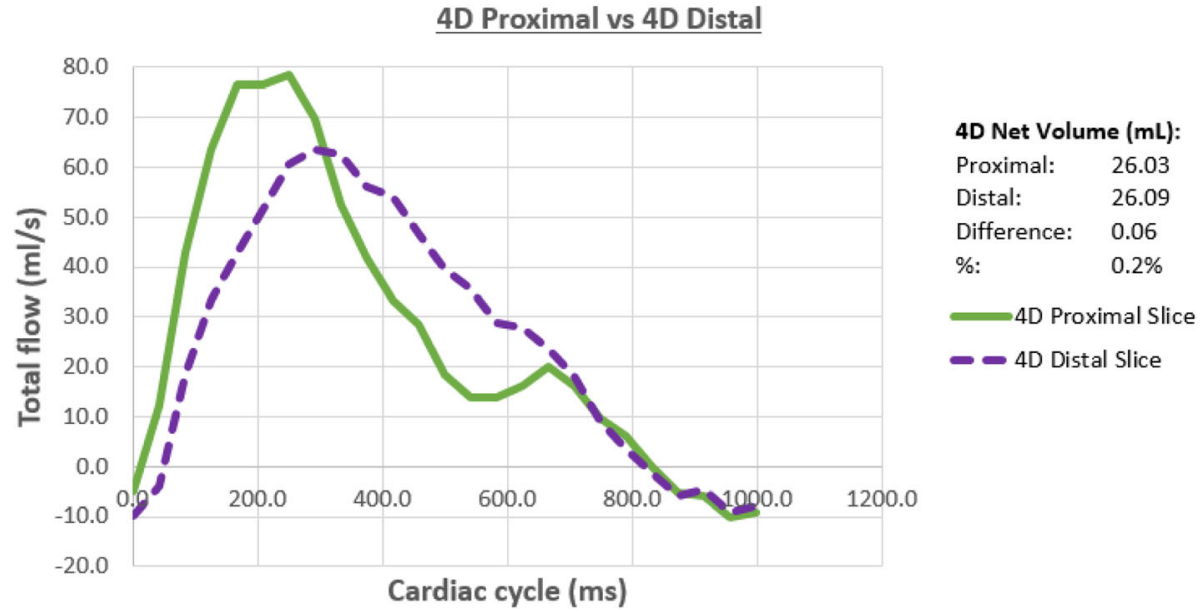

Fig. 7 Correlation of blood flow volumes through the phantom proximal and distal to the aortic valve measured by 2D and 4D phase contrast imaging. There is better consistency of flow volumes in $4 \mathrm{D}$ than the $2 \mathrm{D}$ phase-contrast MRI measurements

of the flow pump and circuit. The current commercially available 3D print material used to generate the valve phantoms does not have identical elastic, strength or biochemical properties to human valve tissue and will remain a limitation of this method until improved materials are available. While we were able to fabricate the valve leaflets with $0.6 \mathrm{~mm}$ thickness with the current commercially available print material, the forthcoming materials allow for fabrication of valve leaflets with a much more realistic $0.3 \mathrm{~mm}$ thickness $[9,19]$. The use of a compliance chamber within the circuit, instead of an open circuit, would also improve the ability to control diastolic pressures being a more accurate reflection of physiological conditions. Although MRI has been proven to be a useful and accurate tool for flow assessment, further validation of 2D- and 4D flow -MRI is required in a larger number of phantom studies. Echocardiography can also be used as an additional modality to confirm the finding found on MR. This would be particularly useful in invivo studies where MR availability may be limited.

\section{Future directions}

Further experimentation with anatomically accurate phantoms will potentially advance our understanding of physiological valve function. With valve repairs being more desirable than replacements, particularly in the pediatric population; this methodology could potentially be used to assess the efficacy and durability of current novel aortic valve repair techniques prior to performing these complex procedures. Additionally, it may provide a safe platform to develop and validate future surgical valve repair techniques. Prior to patient translation, tissue engineering with in-vivo animal studies is the next step to validate this methodology. Tissue-engineered valves will address issues of biocompatibility and valve leaflet durability with the $3 \mathrm{D}$-printed phantoms providing 


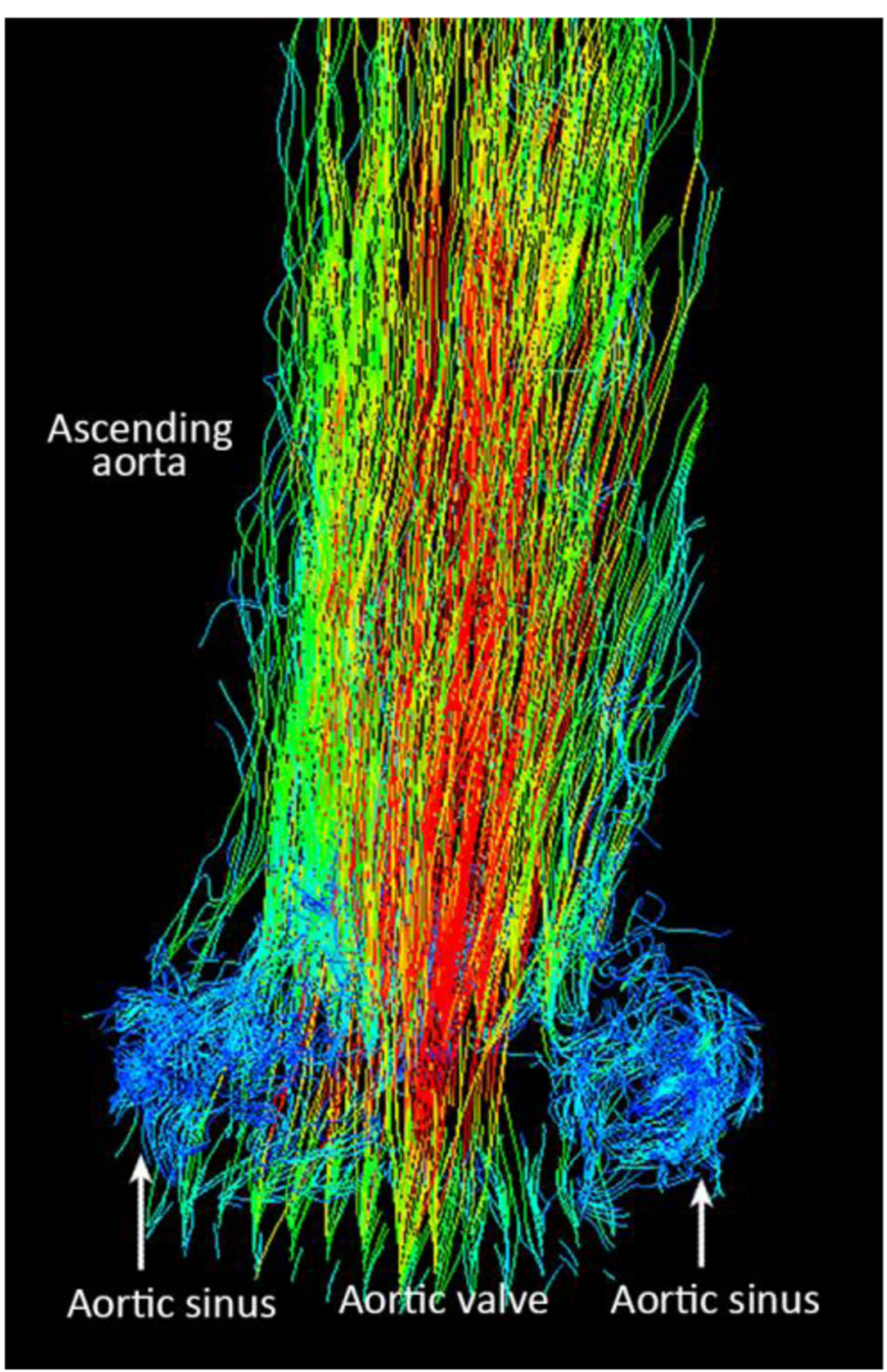

Fig. 8 Particle tracing of flow from 4D phase-contrast MRI showing vortices in the aortic sinuses. Seeds were placed at the aortic valve orifice (Corresponding video file attached - Additional file 3: Video S3)

accurate geometric data for valve scaffolds with favourable flow dynamics.

\section{Conclusion}

In this proof of concept study, we have demonstrated the ability to use existing geometric aortic valve data to generate physiological $3 \mathrm{D}$-printed aortic valve phantoms and evaluate their function with cine- and 4D Flow MRI. This methodology could be used to improve our understanding of the function of the semilunar valves and develop the correct geometry to achieve optimal flow dynamics. It also supports quantitative assessment of specific factors affecting valve function, such as the number of valve leaflets, the configuration of the sinuses of Valsalva, dilatation of the aortic root or pulmonary trunk and coronary artery perfusion during leaflet coaptation. This technology can work synergistically with the promising tissue engineering research in the quest to develop optimal aortic valve replacements, which most closely reproduces the complex function of the normal aortic valve.

\section{Supplementary information}

Supplementary information accompanies this paper at https://doi.org/10 1186/s41205-020-0057-8. 
Additional file 1: Video S1. View from above the 3D printed aortic valve demonstrating the valve closing and opening in response to pulsatile flow.

Additional file 2: Video S2. Cine $M R I$ images showing aortic valve phantom in simulated systole in short (A) and long axis planes (B).

Additional file 2: Video S2. Cine MRI images showing aortic valve phantom in simulated systole in short (A) and long axis planes (B).

Additional file 3: Video S3. Particle tracing of flow from 4D phasecontrast MRI showing vortices in the aortic sinuses. Seeds were placed at the aortic valve orifice.

\section{Abbreviations}

4D: 4-dimensional; CAD: Computer-aided design; CFD: Computational fluid dynamics; MRI: Magnetic resonance imaging; STL: Stereolithography; TAVR: Transcatheter aortic valve replacement

\section{Acknowledgements}

Not applicable.

\section{Authors' contributions}

$\mathrm{NH}$ lead the project and created the semilunar valve models, organized/ performed the experiments and lead the writing of the manuscript. PVN and BP used computer-aided design and 3D printing to develop semilunar valve models and assisted during MR experimentation. SP led the MRI experiments and with ES analyzed and interpreted the MR data sets. CM leads the MRI research team and contributed to the experimental setup and critique to the manuscript. SJY is the principle supervisor who developed the idea and methodology for the experiment and provided the support and facilities to develop the phantoms and testing. All authors read and approved the final manuscript.

\section{Funding}

The Cardiac 3D Printing Program at the Hospital for Sick Children is generously supported through the work of Mr. Peter and Mrs. Fabiola Butler.

\section{Availability of data and materials}

All data generated or analysed during this study are included in this published article.

\section{Ethics approval and consent to participate}

Not applicable.

\section{Consent for publication}

Not applicable.

\section{Competing interests}

The authors declare that they have no competing interests.

\section{Author details}

${ }^{1}$ Division of Cardiology, Department of Paediatrics and Division of Cardiovascular Surgery, Department of Surgery, Hospital for Sick Children, University of Toronto, Toronto, Ontario, Canada. ${ }^{2}$ Center for Image-Guided Innovation and Therapeutic Intervention (CIGITI), Hospital for Sick Children, University of Toronto, Toronto, Ontario, Canada. ${ }^{3}$ Medical Biophysics \& Medical Imaging, Hospital for Sick Children, University of Toronto, Toronto, Ontario, Canada. ${ }^{4}$ Department of Diagnostic Imaging and Division of Cardiology, Department of Paediatrics Hospital for Sick Children, University of Toronto, 555 University Avenue, Toronto, Ontario M5G1X8, Canada.

Received: 17 September 2019 Accepted: 23 January 2020

Published online: 03 February 2020

\section{References}

1. Swanson WM, Clark RE. Dimensions and geometric relationships of the human aortic valve as a function of pressure. Circ Res. 1974;35(6):871-82.

2. Jatene $M B$, et al. Aortic valve assessment. Anatomical study of 100 healthy human hearts. Arq Bras Cardiol. 1999;73(1):81-6.

3. Thubrikar M. The aortic valve. Boca Raton: CRC Press; 1990. p 221, illustrated ISBN: 0-8493-4771-8.
4. Shi WY, O'Keefe M, Matalanis G. Valve-Sparing Aortic Root Replacement and Aortic Valve Repair. Aortic Valve Surg. 2011;1:87.

5. Kunihara T. Anatomy of the aortic root: implications for aortic root reconstruction. Gen Thorac Cardiovasc Surg. 2017:65(9):488-99.

6. Ovcharenko EA, et al. Computer-aided design of the human aortic root. Comput Biol Med. 2015;54:109-15.

7. Crooke PS, Beavan LA, Griffin CD, Mazzitelli D, Rankin JS. A geometric model of the normal human aortic root and design of a fully anatomic aortic root graft. Innov Technol Tech Cardiothorac Vasc Surg. 2015;10(1):57-62.

8. Li KYC. Bioprosthetic Heart Valves: Upgrading a 50-Year Old Technology. Front Cardiovasc Med. 2019;6:1-6.

9. Kheradvar A, et al. Emerging trends in heart valve engineering: part II. Novel and standard Technologies for Aortic Valve Replacement. Ann Biomed Eng. 2015;43(4):844-57.

10. Borger MA, Ivanov J, Armstrong S, Christie-Hrybinsky D, Feindel CM, David TE. Twenty-year results of the Hancock II bioprosthesis. J Heart Valve Dis. 2006;15(1):49-55; discussion 55-6.

11. Lindman BR, Clavel MA, Mathieu P et al. Calcific aortic stenosis. Nat Rev Dis Prim. 2016;2:160006. https://doi.org/10.1038/nrdp.2016.6.

12. Van Der Linde $D$, et al. Birth prevalence of congenital heart disease worldwide: a systematic review and meta-analysis. J Am Coll Cardiol. 2011; 58(21):2241-7.

13. Khan A, Gurvitz M. Epidemiology of ACHD: what has changed and what is changing? Prog Cardiovasc Dis. 2018:61(3-4):275-81.

14. Qian Z, et al. Quantitative prediction of paravalvular leak in Transcatheter aortic valve replacement based on tissue-mimicking 3D printing. JACC Cardiovasc Imaging. 2017;10(7):719-31.

15. Spühler JH, Jansson J, Jansson N, Hoffman J. 3D fluid-structure interaction simulation of aortic valves using a unified continuum ALE FEM model. Front Physiol. 2018;9:1-16.

16. Berdajs D, Mosbahi S, Strano F, Forro Z, Burki M, von Segesser LK. Impact of synthetic elements on aortic root haemodynamics: computed fluid dynamics of aortic root reconstruction and valve reimplantation. Eur $\lrcorner$ Cardiothorac Surg. 2017;51(3):432-41.

17. Berdajs D, Mosbahi S, Eckstein FS, Charbonnier D, Ferrari E, Von Segesser LK. Impact of the bicuspid aortic valve on aortic root haemodynamics: threedimensional computed fluid dynamics simulation. Interact Cardiovasc Thorac Surg. 2018;27(3):446-54.

18. Singh SD, et al. Aortic flow patterns before and after personalised external aortic root support implantation in Marfan patients. J Biomech. 2016;49(1): 100-11.

19. Sulejmani F, Caballero A, Martin C, Pham T, Sun W. Evaluation of transcatheter heart valve biomaterials: Computational modeling using bovine and porcine pericardium. J Mech Behav Biomed Mater. 2019;97:159-70.

\section{Publisher's Note}

Springer Nature remains neutral with regard to jurisdictional claims in published maps and institutional affiliations.
Ready to submit your research? Choose BMC and benefit from:

- fast, convenient online submission

- thorough peer review by experienced researchers in your field

- rapid publication on acceptance

- support for research data, including large and complex data types

- gold Open Access which fosters wider collaboration and increased citations

- maximum visibility for your research: over $100 \mathrm{M}$ website views per year

At BMC, research is always in progress.

Learn more biomedcentral.com/submission 